As a result of oil hydration, waste is formed - phosphatide concentrate, which is a multicomponent system. Valuable components of the concentrate are vegetable oil and phosphatides, the separation of which is an urgent task for the industry.

The process of treatment of sunflower phosphatide concentrate with citric acid (hydration) in order to more completely convert non-hydrated forms of phosphatides into hydrated ones and separate the oil from the concentrate was studied.

A feature of the work is the study of the dependence of the yield and mass fraction of moisture in the extracted oil on the hydration process parameters.

A sample of phosphatide concentrate with non-standard quality indicators according to SOU 15.4-37-212:2004 (CAS 3436-44-0) was studied: the mass fraction of moisture and volatile substances was $4.0 \%$, the mass fraction of phosphatides was $37.0 \%$.

The concentrate was treated with citric acid solution at a temperature of $45^{\circ} \mathrm{C}$ (10\% solution). Rational conditions for concentrate treatment were determined: duration (25 min) and citric acid concentration in relation to the mass of phosphatide concentrate (25\%). Under these conditions, the oil yield was $76.1 \%$, the mass fraction of moisture in the oil was $18.6 \%$. The indicators characterizing the suitability of the oil for consumption and its safety for the body are within the limits (acid value $3.7 \mathrm{mg} \mathrm{KOH} / \mathrm{g}$, peroxide value $5.1 \frac{1}{2} \mathrm{O} \mathrm{mmol} / \mathrm{kg}$ ) for the first-grade unrefined unwinterized sunflower oil according to DSTU 4492. Such oil can be used for refining, fatty acids and biodiesel production, and after additional purification - for processing into food products.

The results of the study make it possible to use resources rationally and predict the yield and quality of the oil isolated from the phosphatide concentrate. The resulting oil can be an affordable raw material for various industries

Keywords: hydration waste, phosphatide concentrate, citric acid, acid value, peroxide value
UDC 665.1

DOI: $10.15587 / 1729-4061.2022 .251034$

\title{
DETERMINATION OF RATIONAL CONDITIONS FOR OIL EXTRACTION FROM OIL HYDRATION WASTE
}

\author{
O Iga Bliznjuk \\ Corresponding author \\ Doctor of Technical Sciences, Professor, Head of Department* \\ E-mail: onbliznjuk@ukr.net \\ Nataliia Masalitina \\ $\mathrm{PhD}$, Associate Professor* \\ Liliia Myronenko \\ $\mathrm{PhD}$ * \\ Oksana Zhulinska \\ $\mathrm{PhD}$ \\ Cycle Commission Hotel and Restaurant Business
} Separate Structural Subdivision "Housing and Municipal Professional College of O. M. Beketov National University of Urban Economy in Kharkiv"

Shevchenka str., 233 A, Kharkiv, Ukraine, 61033

Tatyana Denisenko

$\mathrm{PhD}$

Department of Physical, Organic and Inorganic Chemistry Oles Honchar Dnipro National University Gagarin ave., 72, Dnipro, Ukraine, 49010

Serhii Nekrasov $\mathrm{PhD}$

Department of Manufacturing Engineering, Machines and Tools Sumy State University

Rymskoho-Korsakova str., 2, Sumy, Ukraine, 40007

Serhii Stankevych

$\mathrm{PhD}$

Department of Entomology, Phytopathology, Integrated Plant Protection and Quarantine B. M. Litvinova**

Oleksandr Bragin $\mathrm{PhD}$

Department of Genetics, Breeding and Seed Growing** Oleksii Romanov $\mathrm{PhD}$

Department of Horticulture and Storage of Agricultural Products** Tetiana Romanova $\mathrm{PhD}$

Department of Agrochemistry** *Department of Biotechnology, Biophysics and Analytical Chemistry National Technical University "Kharkiv Polytechnic Institute" Kyrpychova str., 2, Kharkiv, Ukraine, 61002

** State Biotechnological University Alchevsky str., 44, Kharkiv, Ukraine, 61002

How to Cite: Bliznjuk, O., Masalitina, N., Myronenko, L., Zhulinska, O., Denisenko, T., Nekrasov, S., Stankevych, S., Bragin, O., Romanov, O., Romanova, T. (2022). Determination of rational conditions for oil extraction from oil hydration waste. Eastern-European Journal of Enterprise Technologies, 1 (6 (115)), 17-23. doi: https://doi.org/10.15587/1729-4061.2022.251034

\section{Introduction}

Secondary resources of the processing industries of the agro-industrial complex have great potential. The industry, processing multicomponent raw materials, mainly removes one component from them. In this case, the raw materials are used by $15-40 \%$. The rest remain in the form of secondary resources containing a significant number of valuable components that can be used in various fields [1]. It is advisable to involve secondary resources of the industry, in particular, the fat and 
oil industry, in the economic circulation for the production of additional food, feed and technical products or additional components to them.

The fat and oil industry has significant reserves to increase the level of integrated use of raw materials and secondary resources. The implementation of effective production technology is associated with a directed impact on the capillary-porous structure of oilseeds by physical and biological methods. Thus, the development of the fat and oil industry provides for the selection of high-oil, disease-resistant varieties of oilseeds; improvement of cultivation, harvesting and post-harvesting treatment technologies. Of great importance is the creation of highly efficient low- and zero-waste technologies for the production of vegetable oils, the development of new advanced equipment and hardware for oil extraction and processing, etc. An urgent issue is the development and implementation of automation devices and systems in the production of quality products of the fat and oil industry [2].

Typical by-products of hydration are phosphatide emulsion and phosphatide concentrate, a product of emulsion dehydration at a temperature of $75-90{ }^{\circ} \mathrm{C}$ and residual pressure of $2.66 \mathrm{kPa}$ [3]. Due to the process peculiarities, these products contain a high amount of neutral oil. Improving the technology of hydration waste processing for maximum oil extraction from phosphatide concentrate will reduce waste, optimize production modes, and allow rational use of material resources.

Thus, in order to improve the technical and economic performance of hydration of vegetable oil phospholipids, it is advisable to improve the technology of high-quality phosphatide concentrates with the extraction of neutral oil. Of great importance is to increase the concentration of phospholipids in the commercial form of the product. This area of research is important for the industry, as many industries need affordable raw materials of fatty nature.

\section{Literature review and problem statement}

The main product of the fat and oil industry is the oil of various degrees of purification. At the same time, a limited number of manufacturers produce phosphatide concentrates or lecithins as marketable products. Raw materials processed for these purposes include sunflower, rapeseed, soybeans. At the same time, the enterprises of the fat and oil industry have significant volumes of by-products of refining vegetable oils by hydration [4].

Vegetable oils contain a significant amount of phosphatides: sunflower $0.2-1.4 \%$, cottonseed $0.5-2.5 \%$, soybean up to $3.5 \%$. During hydration, fats are treated with water or weak solutions of salts, acids, alkalis, tannins and some other substances. Water, interacting with hydrophilic groups of phosphatides, causes the formation of specific double layers: on the one hand, each of them contains a monomolecular layer of acylglycerols, on the other, a layer of hydrated molecules of phosphatides. This layer, formed by hydration of fats, the so-called hydration precipitate, or fuse, along with phosphatides, contains acylglycerols and leads to the formation of a significant amount of sludge in enterprises. The by-product is almost not used, and is subject to disposal if stored for a long time. Phospholipids can be extracted from oils in various ways, but all of them lead to significant losses of neutral oil with a hydration precipitate. In the refining technology, the phosphatide emulsion is usually mixed with soapstocks, which significantly reduces the consumer value of the mixture. Phosphatides are easily oxidized by oxygen. They contain unsaturated acids in the molecule, which intensifies the spoilage of vegetable fats. During storage of vegetable oils, phosphatides are hydrolyzed to fatty acids, glycerin and phosphoric acid. The hydrolysis of lecithin produces trimethylamine having a fish oil smell that spoils the product [5].

Most phospholipids produced do not provide for long-term storage, have inappropriate color, acidity and viscosity [6].

Plant phospholipids are a complex of individual groups of phospholipids, each exhibiting a unique physiological activity and having specific functional properties [7]. According to [8], lecithin is a complex organic substance of the phospholipid group, which by chemical structure is a complex ester of glycerol and fatty acids, including phosphoric acid and nitrogenous substances. Lecithins are obtained by physical methods from animals or nutrients of plant origin. These natural energy substrates have a unique biopotential and can be used for the production of essential phospholipids and fractionated lecithins, functional foods, dietary supplements and phospholipid substances. Such food concentrates are used in the production of margarine, confectionery, bakery and other products [9].

There is a method in which the phosphatide concentrate obtained by standard technology can be further "improved" to obtain a higher-quality product [10]. To do this, the phosphatide concentrate is treated with a peroxide-enzyme system followed by re-dissolution in deodorized oil. This allows obtaining a phosphatide concentrate with an acid value of oil extracted of less than $10 \mathrm{mg} \mathrm{KOH} / \mathrm{g}$, color value - less than $3 \mathrm{mg} \mathrm{J}$. As a result of obtaining a phosphatide concentrate at oil production plants, it is possible to increase the oil yield in the main process and obtain a multifunctional product - phosphatide concentrate. The disadvantage of this method is the high cost and duration of treatment. In addition, there are no data on how to extract oil as a valuable product.

In [11], the technology of degreasing phosphatide concentrate with isopropyl alcohol is proposed. The phosphatide concentrate is treated with isopropyl alcohol in a ratio of 1:2 at the first stage of extraction, and then 1:1 at a temperature of $50-70{ }^{\circ} \mathrm{C}$ and while intensive stirring at three more stages. This technology significantly reduces extractant consumption. But there are no data on the quality and amount of oil separated from phospholipids. There is also a method of separating phospholipids from oil by dissolving them in hexane followed by hydration with water [12]. But the effect of this method and process modes on oil extraction is also not shown.

The authors of [13] propose a method that involves treating the oil with a hydrating agent, exposing the mixture, separating the phosphatide emulsion from the hydrated oil and drying the phosphatide emulsion. Moreover, after separating the phosphatide emulsion, whey is added to it in an amount of 3.0-7.0 \% by weight of the phosphatide emulsion. Then it is heated to a temperature of $70-80{ }^{\circ} \mathrm{C}$, separated into aqueous and fatty phases, the fat phase is separated and dried to obtain phosphatide concentrate. The technology allows obtaining high-quality phosphatide concentrate with low acid and peroxide values. The disadvantage of the study is the focus only on obtaining phosphatides. But oil is also an important component of the phosphate emulsion.

There is a method [14] of obtaining phosphatide concentrate by mixing unrefined oil with a hydrating agent in the 
amount necessary for complete removal of phospholipids. Next, the mixture is exposed, the phosphatide emulsion is separated from the hydrated oil, and the hydrated oil and the phosphatide emulsion are dried. The disadvantages of this method include the high acid and peroxide values of the oil isolated from the phospholipid product, and a long drying time of the emulsion.

In [15], a continuous technology for the purification of phosphatide concentrate by magnetoacoustic method for separating modified distillates of sunflower oil to obtain lecithins with a high content of phosphatidylcholines was developed. Distillation of a selective solvent, ethyl alcohol, and adsorption by silica gel were used in the work, and to increase their solubility and absorption capacity, ultrasound with an intensity of $10 \mathrm{~W} / \mathrm{m}^{2}$ was applied. This batch treatment provides a substantially discolored granular lecithin-containing product in the form of microgranules of an alcohol-insoluble fraction and a liquid fat-containing part, partially absorbed by silica gel. But the work investigated the method of obtaining only phosphatides. There are no data on the use of the results for oil extraction.

There are technologies of phosphatide concentrate treatment with the extraction of phospholipids from the mixture. In particular, a promising method to obtain high-quality phosphatide products is to extract them with ethyl alcohol from phosphatide concentrates. The process of separation of phosphatide concentrates takes place in ethyl alcohol at a concentration of up to $1: 12$ and an elevated temperature of the mixture of about $60{ }^{\circ} \mathrm{C}$ to obtain alcohol-soluble and alcohol-insoluble fractions. After vacuum drying, a concentrated fat-oil phosphatide product with a characteristic odor and intense color is obtained [16].

Thus, the substantiation of approaches to improving the chemical-technological processes of separating phosphatide emulsions and increasing the treatment depth of phosphatide fractions, which are part of unrefined vegetable oils, is an urgent task. However, there is not enough data on the development of technologies for oil extraction from phosphatide emulsions, as well as the impact of emulsion treatment parameters on the quality and amount of oil. An important issue is rational treatment conditions of oil hydration waste, which will allow efficient use of enterprise resources to obtain high-quality products, in particular, oil, for various industries.

\section{The aim and objectives of the study}

The aim of the study is to develop rational conditions of treatment of phosphatide sunflower concentrate with citric acid solution. This will increase the efficiency of treatment of oil hydration waste (phosphatide concentrate) with citric acid to obtain a valuable component - oil, which can be used in various fields.

To achieve the aim, the following objectives were set:

- to determine the organoleptic and physicochemical parameters of an experimental sample of phosphatide sunflower concentrate;

- to determine the influence of treatment conditions of phosphatide concentrate on the yield and mass fraction of moisture of the extracted oil and determine rational conditions for phosphatide concentrate treatment;

- to determine the quality of oil extracted from phosphatide concentrate under rational conditions.

\section{Research materials and methods}

4. 1. Examined materials and equipment used in the experiment

The following reagents and materials were used:

- phosphatide sunflower concentrate according to SOU 15.4-37-212: 2004 (CAS 3436-44-0);

- food grade citric acid according to DSTU GOST 908: 2006 (CAS 77-92-9).

4.2. Method of determining the organoleptic and physicochemical indicators of the experimental sample of phosphatide concentrate

Organoleptic and physicochemical indicators of the experimental sample of phosphatide concentrate were determined by standard methods according to SOU 15.4-37-212: 2004.

4. 3. Method of phosphatide concentrate treatment with citric acid solution

A portion of phosphatide concentrate was placed in a heat-resistant beaker mounted on an electric stove. A stirrer and a thermometer were placed in the beaker. A $10 \%$ citric acid solution was added. Hydration was performed at a temperature of $45^{\circ} \mathrm{C}$ with stirring. The amount of citric acid in relation to the mass of phosphatide concentrate and the process duration in the experiments corresponded to the experimental plan. After hydration, the mass was settled for 3 hours at $45^{\circ} \mathrm{C}$, then the upper layer (oil), the middle layer (phosphatides) and the lower layer (aqueous component with citric acid) were separated.

4. 4. Method of determining the quality of oil isolated from phosphatide concentrate

The transparency, taste and smell of the oil are determined by standard methods according to DSTU 8842: 2019 (AOCS Cg 2-83). The acid value, peroxide value, mass fraction of phosphorus-containing substances, mass fraction of moisture and volatile substances are determined by standard methods according to DSTU 4350 (ISO 660), DSTU 4570 (ISO 3960), DSTU 7082 (ISO 10540-3), DSTU 4603 (ISO 662), respectively.

\section{5. Research planning and processing of results}

A complete second-order factorial experiment was used for research planning and mathematical data processing. Processing of scientific results, construction of graphical dependences were performed in Stat Soft Statistica v6.0 (USA). Each experiment was performed twice.

\section{Results of studying the influence of phosphatide concentrate treatment conditions on oil extraction efficiency}

5. 1. Determination of organoleptic and physicochemical indicators of phosphatide sunflower concentrate

Organoleptic and physicochemical indicators of the experimental sample of phosphatide sunflower concentrate are given in Table 1.

So, the experimental sample of phosphatide sunflower concentrate is close to phosphatide fodder concentrate (SnK grade) according to SOU 15.4-37-212: 2004. But the indicators of the sample (except for acid and peroxide values) deviate from the 
norm. Thus, a non-standard sample of phosphatide concentrate was used to extract the valuable product - oil.

Table 1

Organoleptic and physicochemical indicators of the phosphatide concentrate sample

\begin{tabular}{|c|c|}
\hline Indicator & Characteristic \\
\hline \multicolumn{2}{|c|}{ Organoleptic indicators } \\
\hline Odor and taste & $\begin{array}{l}\text { The odor is typical for } \\
\text { sunflower oil, without } \\
\text { mustiness and other } \\
\text { foreign odors. The taste is } \\
\text { inherent in phosphatides }\end{array}$ \\
\hline Consistency & Pasty \\
\hline \multicolumn{2}{|c|}{ Physicochemical indicators } \\
\hline $\begin{array}{l}\text { Mass fraction of moisture and volatile } \\
\text { substances, } \%\end{array}$ & 4.0 \\
\hline Mass fraction of phosphatides, $\%$ & 37.0 \\
\hline Mass fraction of oil, $\%$ & 65.5 \\
\hline $\begin{array}{c}\text { Mass fraction of substances insoluble } \\
\text { in ethyl ether, \% }\end{array}$ & 5.2 \\
\hline $\begin{array}{l}\text { Acid value of the oil extracted from } \\
\text { the concentrate, } \mathrm{mg} \mathrm{KOH} / \mathrm{g}\end{array}$ & 18.2 \\
\hline $\begin{array}{l}\text { Peroxide value of the oil extracted } \\
\text { from the concentrate, } 1 / 2 \mathrm{O} \mathrm{mmol} / \mathrm{kg}\end{array}$ & 24.7 \\
\hline
\end{tabular}

5. 2. Determination of the influence of phosphatide concentrate treatment conditions on oil extraction efficiency

In order to separate oil from the phosphatide concentrate, a $10 \%$ citric acid solution was used. Citric acid is used in oil hydration to more fully concentrate phosphatides and convert non-hydrated forms of phosphatides to hydrated ones. In the study, citric acid was used to more effectively separate oil from the concentrate. The influence of conditions of phosphatide concentrate treatment by citric acid (hydration) on the yield and mass fraction of moisture of the isolated oil is determined. Conditions of the factorial experiment: number of factors -2 , number of factor variation levels -5 , number of experiments -25 . Factors and intervals of variation:

$-x_{1}$ - concentration of citric acid relative to the mass of phosphatide concentrate: from 5 to $25 \%(5,10,15,20,25 \%)$;

$-x_{2}$ - hydration duration: from 5 to 45 minutes $(5,15$, 25, 35, 45 minutes).

The response functions are the yield (as a percentage of oil in the phosphatide concentrate) and mass fraction of moisture in the oil.

The research results were processed in the Stat Soft Statistica v6.0 package (USA). Second-order regression equations, which are the dependences of the response functions on the hydration process parameters, are calculated.

The regression dependence of oil yield $\left(y_{1}\right)$ on hydration conditions in real variables has the form:

$$
\begin{aligned}
& y_{1}=33.116+0.585 \cdot x_{1}+0.699 \cdot x_{2}+ \\
& +0.031 \cdot x_{1}^{2}-0.009 \cdot x_{1} \cdot x_{2}-0.005 \cdot x_{2}^{2}
\end{aligned}
$$

The regression dependence of the mass fraction of moisture in the extracted oil $\left(y_{2}\right)$ on hydration conditions in real variables has the form:

$$
\begin{aligned}
& y_{2}=31.499-0.457 \cdot x_{1}-0.164 \cdot x_{2}+ \\
& +0.015 \cdot x_{1}^{2}-0.013 \cdot x_{1} \cdot x_{2}+0.003 \cdot x_{2}^{2} .
\end{aligned}
$$

The significance level of the coefficients of equations $(p>0.05)$ and the coefficients of determination, which were 0.967 and 0.912 for equations (1) and (2), respectively, were determined.

Table 2 shows the experiment planning matrix, experimental and calculated values of the response functions. The calculated values of the response functions are obtained by

\begin{tabular}{|c|c|c|c|c|c|c|}
\hline \multirow{2}{*}{$\begin{array}{l}\text { Ex- } \\
\text { peri- } \\
\text { ment } \\
\text { num- } \\
\text { ber }\end{array}$} & \multicolumn{2}{|c|}{$\begin{array}{l}\text { Factors of vari- } \\
\text { ation }\end{array}$} & \multicolumn{2}{|c|}{$\begin{array}{c}\text { Experimental } \\
\text { values of response } \\
\text { functions }\end{array}$} & \multicolumn{2}{|c|}{$\begin{array}{c}\text { Calculated values } \\
\text { of response func- } \\
\text { tions } \\
\end{array}$} \\
\hline & $\begin{array}{l}\text { Citric } \\
\text { acid } \\
\text { con- } \\
\text { centra- } \\
\text { tion, \% }\end{array}$ & $\begin{array}{l}\text { Hydra- } \\
\text { tion } \\
\text { dura- } \\
\text { tion, } \\
\text { min }\end{array}$ & $\begin{array}{c}\text { Oil } \\
\text { yield, \% }\end{array}$ & \begin{tabular}{|c} 
Mass \\
frac- \\
tion of \\
moisture \\
in the \\
oil, $\%$ \\
\end{tabular} & $\begin{array}{c}\text { Oil } \\
\text { yield, \% }\end{array}$ & $\begin{array}{l}\text { Mass } \\
\text { fraction } \\
\text { of mois- } \\
\text { ture } \\
\text { in the } \\
\text { oil, } \% \\
\end{array}$ \\
\hline 1 & 5 & 5 & 39.1 & 29.1 & 41.7 & 31.0 \\
\hline 2 & 5 & 15 & 47.9 & 28.3 & 46.5 & 28.2 \\
\hline 3 & 5 & 25 & 52.5 & 27 & 50.3 & 26.0 \\
\hline 4 & 5 & 35 & 54.2 & 26.2 & 53.1 & 24.6 \\
\hline 5 & 5 & 45 & 54.8 & 25.2 & 55.0 & 23.8 \\
\hline 6 & 10 & 5 & 42.9 & 25.7 & 45.9 & 28.3 \\
\hline 7 & 10 & 15 & 49.2 & 23.6 & 50.7 & 25.5 \\
\hline 8 & 10 & 25 & 54.8 & 22.3 & 54.4 & 23.3 \\
\hline 9 & 10 & 35 & 54.3 & 22.2 & 57.3 & 21.8 \\
\hline 10 & 10 & 45 & 56.9 & 21.2 & 59.2 & 21.0 \\
\hline 11 & 15 & 5 & $\begin{array}{l}53.8 \\
\end{array}$ & 25.2 & 51.7 & 26.3 \\
\hline 12 & 15 & 15 & 58.4 & 23.3 & 56.4 & 23.5 \\
\hline 13 & 15 & 25 & 62.4 & $\begin{array}{l}21.3 \\
\end{array}$ & 60.2 & 21.3 \\
\hline 14 & 15 & 35 & 66.9 & 21.1 & 63.0 & 19.8 \\
\hline 15 & 15 & 45 & 71.1 & 20.9 & 64.9 & 19.1 \\
\hline 16 & 20 & 5 & 56.5 & 27.8 & 59.0 & 25.1 \\
\hline 17 & 20 & 15 & 60.1 & 23.9 & 63.7 & 22.2 \\
\hline 18 & 20 & 25 & 64.2 & 19.3 & 67.5 & 20.1 \\
\hline 19 & 20 & 35 & 67.5 & 17.6 & 70.4 & 18.6 \\
\hline 20 & 20 & 45 & 72.2 & 17.7 & 72.3 & 17.8 \\
\hline 21 & 25 & 5 & 73.4 & 27.3 & 67.9 & 24.5 \\
\hline 22 & 25 & 15 & 75.1 & 22.8 & 72.6 & 21.7 \\
\hline 23 & 25 & 25 & 76.1 & 18.6 & 76.4 & 19.6 \\
\hline 24 & 25 & 35 & 77.8 & 17.4 & 79.3 & 18.1 \\
\hline 25 & 25 & 45 & 78.5 & 13.5 & 81.2 & 17.3 \\
\hline
\end{tabular}
equations (1) and (2).

Table 2

Planning matrix and values of response functions

Graphical dependences of the response functions on hydration conditions (response surface) are constructed, as shown in Fig. 1, 2.

From Table 2, equation (1) and Fig. 1, it is found that with increasing citric acid concentration and hydration duration, the oil yield increases. The concentration of citric acid has a more significant effect on the oil yield than the duration. At a citric acid concentration of $25 \%$ with increasing duration from 5 to 45 minutes, starting from 15 minutes, there is no significant increase in response function. Therefore, the rational conditions in this case are the citric acid concentration of $25 \%$, hydration duration of 15 minutes. 


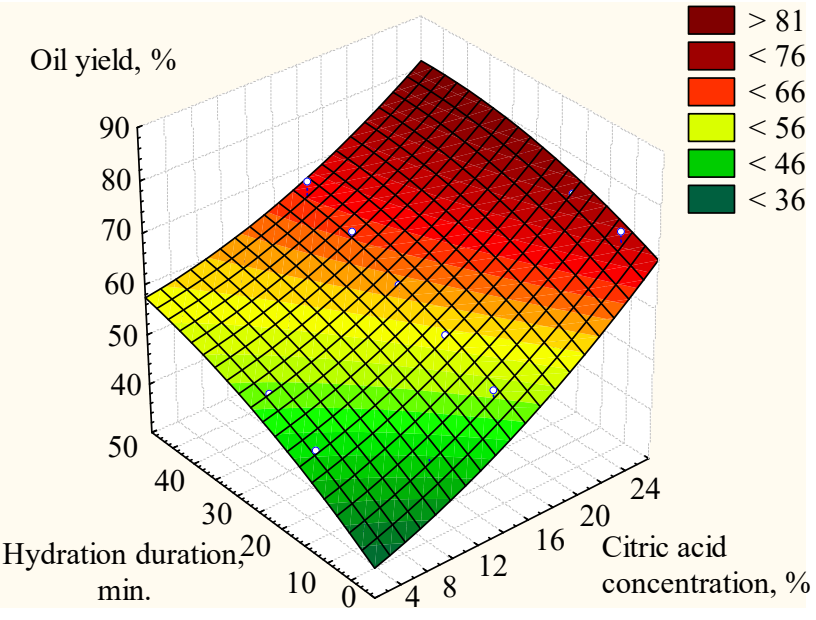

Fig. 1. Dependence of extracted oil yield on citric acid concentration and hydration duration (response surface)

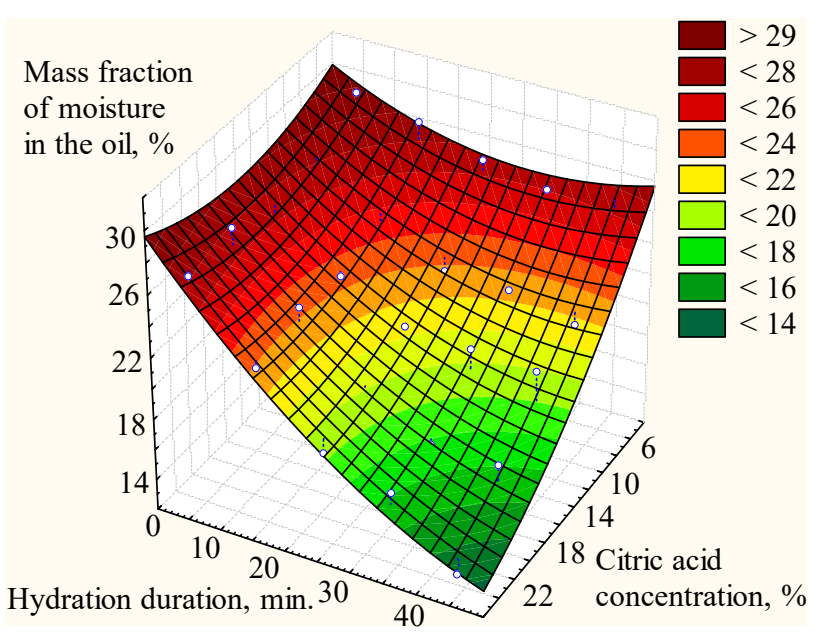

Fig. 2. Dependence of the mass fraction of moisture in the isolated oil on citric acid concentration and hydration duration

According to Table 2, equation (2) and Fig. 2, with increasing variation factors, the mass fraction of moisture in the oil decreases, indicating an increase in the efficiency of separation of phosphatides and oil. The duration has a more significant effect on the response function. The greatest effect of duration is observed at an acid concentration of $25 \%$. From 25 to 35 minutes, the decrease in the mass fraction of moisture slows down. Taking into account the effect of duration at other acid concentrations, rational conditions are the citric acid concentration of $25 \%$, hydration duration of 25 min. Under these conditions, the oil yield was $76.1 \%$, the mass fraction of moisture in the oil $-18.6 \%$.

5. 3. Determination of quality indicators of oil extracted from phosphatide concentrate

The oil extracted from the phosphatide concentrate was analyzed for basic organoleptic and physicochemical indicators. Before analysis, the oil was washed with $45^{\circ} \mathrm{C}$ water to remove residual citric acid. The oil was then settled for 4 hours, dried in a vacuum at $85-90{ }^{\circ} \mathrm{C}$ to $0.15 \%$ by weight and investigated. The results of the study are given in Table 3.
Table 3

Organoleptic and physicochemical indicators of oil extracted from phosphatide concentrate (after drying)

\begin{tabular}{|c|c|}
\hline Indicator & Characteristic \\
\hline Transparency & $\begin{array}{c}\text { Transparent, no sedi- } \\
\text { ment }\end{array}$ \\
\hline Odor and taste & $\begin{array}{c}\text { Inherent in sunflower oil. } \\
\text { The taste is slightly bitter }\end{array}$ \\
\hline Acid value, $\mathrm{mg} \mathrm{KOH} / \mathrm{g}$ & 3.7 \\
\hline Peroxide value, $1 / 2 \mathrm{O} \mathrm{mmol} / \mathrm{kg}$ & 5.1 \\
\hline $\begin{array}{c}\text { Mass fraction of phosphorus-contain- } \\
\text { ing substances in terms of stearooleo- } \\
\text { lecithin, } \%\end{array}$ & 2.8 \\
\hline $\begin{array}{c}\text { Mass fraction of moisture and volatile } \\
\text { substances, } \%\end{array}$ & 0.15 \\
\hline
\end{tabular}

Thus, the oil extracted from the phosphatide concentrate corresponds to the first-grade unrefined unwinterized sunflower oil according to DSTU 4492. But the mass fraction of phosphorus-containing substances exceeds standard values. Such oil can be used for refining, technical purposes, fatty acids and biodiesel. After additional purification, the oil can be used for industrial processing into food. Indicators that primarily characterize the suitability of the oil for human consumption (acid and peroxide values) are within the norms for the first-grade unrefined unwinterized sunflower oil according to DSTU 4492.

\section{Discussion of the results of studying the influence of phosphatide concentrate treatment conditions on oil extraction efficiency}

The technology of oil extraction from phosphatide sunflower concentrate with non-standard quality indicators, which involves treatment of the concentrate with citric acid solution, has been studied. The influence of the parameters of phosphatide concentrate treatment with citric acid (hydration) on the yield and mass fraction of moisture in extracted oil is determined. Analyzing Table 2, Fig. 1, 2 and equations (1), (2), rational conditions for concentrate treatment are determined: duration (25 min) and citric acid concentration in relation to the mass of phosphatide concentrate (25\%). Under these conditions, the oil yield increased to $76.1 \%$, the mass fraction of moisture in the oil decreased to $18.6 \%$. According to the review of scientific studies [10-16], the main task of processing phosphatide concentrates is to obtain phosphatides. However, there are no data on the development and optimization of technologies for oil extraction from concentrates. Therefore, the study of the process of oil extraction from concentrates, determination of rational conditions for maximum oil yield and reducing the moisture content in the oil are important areas of research. Rational conditions for concentrate treatment are determined by the results of the experiments provided in Table 2.

The work differs from the existing scientific research [10-16] by determining rational conditions for acid hydration of phosphatide concentrate with non-standard indicators (mass fraction of moisture and volatile substances, mass fraction of phosphatides, mass fraction of oil, mass fraction of substances insoluble in ethyl ether) in order to extract oil. This technology will allow efficient separation 
of phosphatides and oil with rational use of resources and predicting the yield and quality of extracted oil.

Phospholipids have a structure of esters, the molecules of which include residues of fatty acids, phosphoric acid and an additional group of atoms containing nitrogen. Phospholipid molecules are diphilic in nature; the hydrophobic part is represented by fatty acid radicals, and the hydrophilic part by polar groups. Therefore, phospholipids are surfactants. Hydration is a chemical method of oil refining, in which oil is treated with water or an acid solution. In the first case, phospholipids add water, lose solubility and are isolated from the oil. In the second case, non-hydrated forms of phospholipids (calcium and magnesium derivatives of phospholipids) are extracted. At the same time, phospholipids break down. Weak electrolyte solutions, in particular sodium chloride, are used to intensify the separation of phospholipids. Therefore, citric acid treatment is promising for efficient separation of oil and phospholipids.

With increasing citric acid concentration and process duration, the oil yield increases, the mass fraction of moisture in the oil decreases. The concentration of citric acid has a more significant effect on the yield, and the duration - on the mass fraction of moisture in the oil. The greatest effect of duration on the mass fraction of moisture in the oil is observed at an acid concentration of $25 \%$. At an acid concentration of $25 \%$ with increasing duration from 5 to 45 minutes, starting from 15 minutes, the yield increases only 1.1 times, and the mass fraction of moisture decreases 2 times. From 25 to 35 minutes, the decrease in the mass fraction of moisture slows down. Taking into account the effect of duration at other acid concentrations, rational conditions are the citric acid concentration of $25 \%$, hydration duration of $25 \mathrm{~min}$.

Increasing the process duration promotes a more efficient and complete interaction of phospholipids with the acid and, as a consequence, a more complete separation of oil. The concentration of citric acid affects the completeness of the process of phospholipids and emulsion destruction, which affects the separation efficiency of phospholipids and oil.

The obtained data reveal a relationship between the treatment parameters of phosphatide concentrate and the efficiency of oil extraction, which will allow rational and efficient processing of oil hydration waste into valuable products. The results of the work contribute to the provision of various industries with affordable raw materials (oil) and solving the problem of fat waste disposal. In particular, the oil extracted from hydration waste can be a raw material for the production of biodiesel from fatty acid esters.

The production use of the obtained scientific results is limited. Treatment of phosphatide concentrate should be carried out under the developed rational conditions. After all, the factors of variation have a significant impact on the yield and moisture of the extracted oil. The need to wash the oil from citric acid and dry it should be taken into account. The presence of acid can distort the results of studies of oil indicators and limit the use of oil in various fields.

The disadvantage of the study is the determination of the effect of hydration parameters only for the oil production process. Phospholipids are also an important component of phosphatide concentrate, which are used in various fields (chemical, food industry, etc.). It is advisable to conduct experiments on the quality of phospholipids obtained by this technology.

Promising areas of research are to determine the influence of hydration parameters on other oil indicators, as well as on the quality and yield of phospholipids. This will allow a comprehensive description of the technology of phosphatide concentrate separation into valuable components, as well as provide information on the use of these components for various purposes.

\section{Conclusions}

1. Organoleptic and physicochemical parameters of the experimental sample of phosphatide sunflower concentrate were determined. The mass fraction of moisture and volatile substances $-4.0 \%$, phosphatides - $37.0 \%$, oil $-65.5 \%$, substances insoluble in ethyl ether $-5.2 \%$. The acid value of the oil extracted from the concentrate is $18.2 \mathrm{mg} \mathrm{KOH} / \mathrm{g}$, the peroxide value of the oil extracted from the concentrate is $24.71 / 2 \mathrm{O} \mathrm{mmol} / \mathrm{kg}$. In terms of quality indicators, phosphatide concentrate is non-standard according to SOU 15.4-37-212:2004 (CAS 3436-44-0).

2 . The influence of treatment conditions of phosphatide concentrate on the yield and mass fraction of moisture of the extracted oil is determined. Rational conditions for concentrate treatment are determined: duration (25 min) and citric acid concentration in relation to the mass of phosphatide concentrate (25\%). Under these conditions, the oil yield was $76.1 \%$, the mass fraction of moisture in the oil was $18.6 \%$.

3. Quality indicators of the oil extracted from phosphatide concentrate under rational conditions were determined. The acid value $-3.7 \mathrm{mg} \mathrm{KOH} / \mathrm{g}$, peroxide value $5.1 \frac{1}{2} \mathrm{O} \mathrm{mmol} / \mathrm{kg}$, mass fraction of phosphorus-containing substances, in terms of stearooleolecithin $-2.8 \%$, mass fraction of moisture and volatile substances $-0.15 \%$. The extracted oil corresponds to the first-grade unrefined unwinterized sunflower oil according to DSTU 4492. But the mass fraction of phosphorus-containing substances exceeds standard values. The oil can be used for refining, technical purposes, fatty acids and biodiesel, after additional purification - for industrial processing into food.

References

1. Galstyan, A. G., Aksyonova, L. M., Lisitsyn, A. B., Oganesyants, L. A., Petrov, A. N. (2019). Modern Approaches to Storage and Effective Processing of Agricultural Products for Obtaining High Quality Food Products. Herald of the Russian Academy of Sciences, 89 (2), 211-213. doi: https://doi.org/10.1134/s1019331619020059

2. Rani, R., Badwaik, L. S. (2021). Functional Properties of Oilseed Cakes and Defatted Meals of Mustard, Soybean and Flaxseed. Waste and Biomass Valorization, 12 (10), 5639-5647. doi: https://doi.org/10.1007/s12649-021-01407-z

3. Casado, V., Martín, D., Torres, C., Reglero, G. (2012). Phospholipases in Food Industry: A Review. Methods in Molecular Biology, 495-523. doi: https://doi.org/10.1007/978-1-61779-600-5_29 
4. Stepycheva, N. V., Makarov, S. V., Kucherenko, P. N. (2012). Secondary material resources of oil-producing plants. Russian Journal of General Chemistry, 82 (5), 969-976. doi: https://doi.org/10.1134/s1070363212050301

5. Küllenberg, D., Taylor, L. A., Schneider, M., Massing, U. (2012). Health effects of dietary phospholipids. Lipids in Health and Disease, 11 (1). doi: https://doi.org/10.1186/1476-511x-11-3

6. Ghouila, Z., Sehailia, M., Chemat, S. (2019). Vegetable Oils and Fats: Extraction, Composition and Applications. Plant Based “Green Chemistry 2.0”, 339-375. doi: https://doi.org/10.1007/978-981-13-3810-6_12

7. Lu, F. S. H., Nielsen, N. S., Baron, C. P., Jensen, L. H. S., Jacobsen, C. (2012). Physico-chemical Properties of Marine Phospholipid Emulsions. Journal of the American Oil Chemists' Society, 89 (11), 2011-2024. doi: https://doi.org/10.1007/s11746-012-2105-z

8. Winkler-Moser, J. K., Mehta, B. M. (2015). Chemical Composition of Fat and Oil Products. Handbook of Food Chemistry, 365-402. doi: https://doi.org/10.1007/978-3-642-36605-5_32

9. Begić, M., Nezirević-Nizić, E., Čorbo, S., Podrug, S., Ašimović, Z., Muminović, Š. (2020). Fatty Acid Composition and Stability of Cold-Pressed Vegetable Oils. IFMBE Proceedings, 303-312. doi: https://doi.org/10.1007/978-3-030-40049-1_39

10. K voprosu o fosfatidnom kontsentrate. APK Inform. Available at: https://www.apk-inform.com/ru/oilprocessing/9778

11. Demidov, I. N., Kramarenko, A. A. (2008). Sposoby polucheniya fosfolipidnykh produktov. Voprosy khimii i khimicheskoy tekhnologii, 2, 58-63. Available at: https://udhtu.edu.ua/public/userfiles/file/VHHT/2008/2/Demidov.pdf

12. Mel'nikov, K. A. (2000). Vydelenie letsitinov iz fosfatidnogo kontsentrata podsolnechnogo masla. Maslozhirovaya promyshlennost', $2,21-22$.

13. Martovschuk, V. I., Martovschuk, E. V., Bagrov, A. A., Zabolotniy, A. V. (2012). Pat. No. 2487162 RU. Sposob polucheniya fosfatidnogo kontsentrata. declareted: 05.03.2012; published: 10.07.2013.

14. Kaya, D., Hung, Y.-T. (2021). Advances in Treatment of Vegetable Oil Refining Wastes. Environmental and Natural Resources Engineering, 325-375. doi: https://doi.org/10.1007/978-3-030-54626-7_8

15. Shestakova, E. A., Raspopov, D. S., Verboloz, E. I. (2019). Development of flow technology for the purification and production of food sunflower phospholipids. Proceedings of the Voronezh State University of Engineering Technologies, 81 (1), 125-131. doi: https://doi.org/10.20914/2310-1202-2019-1-125-131

16. Cerminati, S., Paoletti, L., Aguirre, A., Peirú, S., Menzella, H. G., Castelli, M. E. (2019). Industrial uses of phospholipases: current state and future applications. Applied Microbiology and Biotechnology, 103 (6), 2571-2582. doi: https://doi.org/10.1007/ s00253-019-09658-6 